\title{
Development of Spectrophotometric Method for Quantitative Estimation of Amlodipine Besylate, Olmesartan Medoxomil and Hydrochlorthiazide in Tablet Dosage Form
}

\author{
Hemendra Kumar Sharma*, Nilesh Jain and Surendra Kumar Jain \\ Sagar Institute of Research and Technology-Pharmacy, Ayodhya Bypass Road, Bhopal, M.P, India
}

\begin{abstract}
A new, simple, accurate, precise and reproducible UV spectrophotometric method is being developed for the simultaneous estimation of amlodipine besylate, olmesartan medoxomil and hydrochlorthiazide in tablet dosage form. The stock solutions were prepared in methanol. The $\lambda_{\max }$ for amlodipine besylate, olmesartan medoxomil and hydrochlorthiazide were $238.5 \mathrm{~nm}, 256.5 \mathrm{~nm}$ and $271.5 \mathrm{~nm}$ respectively. The amlodipine besylate, olmesartan

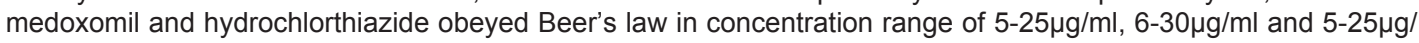
$\mathrm{ml}$ respectively. Results of analysis of simultaneous equation method were analyzed and validated for various parameters according to $\mathrm{ICH}$ guidelines.
\end{abstract}

Keywords: Simultaneous equation method; Amlodipine besylate; Olmesartan medoxomil; Hydrochlorthiazide

\section{Introduction}

Amlodipine besylate (Figure 1a) [1] is 3-Ethyl 5-methyl (4RS)2-[(2-aminoethoxy) methyl]-4-(2-chlorophenyl)-6-methyl-1,4dihydropyridine-3,5-dicarboxylate benzene sulphonate is a calcium channel blocker and widely used in the treatment of hyprtension [5]. Olmesartan medoxomil (Figure 1b) [1] is [2,3-dihydroxy-2-buten yl 4-(1-hydroxy-1-methylethyl)-2-propyl-1-[p-(o-1H-tetrazol-5ylphenyl) benzyl]imidazole-5-carboxylate, cyclic 2,3-carbonate] an angiotensin II receptor blocker (ARB). Olmesartan blocks the vasoconstrictor effects of angiotensin II by selectively blocking the binding of angiotensin II to the AT1 receptor in vascular smooth muscle [5] and Hydrochlorthiazide (Figure 1c) [1] is 6-chloro-3, 4-dihydro-2H-1,2,4-benzothiadiazine-7- Sulphonamide 1, 1-dioxide is diuretic and antihypertensive drug, which inhibits the reabsorption of sodium and calcium at the beginning of distal convoluted tubules [5]. Amlodipine besylate is official in IP [2] and BP [3] and Hydrochlorthiazide is official in IP [2], BP [3] and USP [4]. Literature survey revealed that various methods such as UV $[9,10,15,16,19,20]$, HPLC [11,17], HPTLC [12,18], LC-MS/MS [13] and UPLC [14] are available in single and combination with other drugs. However, no spectrophotometric method has yet been reported for simultaneous estimation of amlodipine besylate, olmesartan medoxomil and hydrochlorthiazide in tablet dosage forms. Hence, an attempt has been made to develop and validate in accordance with ICH guidelines $[7,8]$.

\section{Materials and Methods}

\section{Chemicals}

Pharmaceutically pure sample of amlodipine besylate was obtained from Sun pharmaceuticals, Silvasa(GJ), olmesartan medoxomil was obtained from Plathico pharma Ltd. Dewas and hydrochlorthiazide was obtained from Matrix laboratory Mumbai as gift samples along with there analytical reports. Methanol AR grade was obtained from Merck chemical division, Mumbai and Commercial tablet of amlodipine besylate (5mg), olmesartan medoxomil (20mg) and Hydrochlorthiazide (12.5mg), Olmat-AMH (Micro labs) were procured from the local drug market.

\section{Instrument}

A double beam UV-visible spectrophotometer (SHIMADZU, Japan), model UV-1700 PC was used. The software employed was UV probe version 2.33 . The spectra was recorded over range $200-400 \mathrm{~nm}$ against solvent in $1 \mathrm{~cm}$ quarts cells.

\section{Standard solution preparations}

Accurately weighed $100 \mathrm{mg}$ of amlodipine, olmesartan and hydrochlorthiazide were transferred into $100 \mathrm{ml}$ volumetric flasks separately and dissolved in $50 \mathrm{ml}$ of methanol and then volume was made up to $100 \mathrm{ml}$ with methanol to get a concentration of $1000 \mu \mathrm{g} / \mathrm{ml}$ for all three drugs. Standard stock solution $(1000 \mu \mathrm{g} / \mathrm{ml})$ was further diluted with methanol to obtain $5-25 \mu \mathrm{g} / \mathrm{ml}$ for amlodipine, $6-30 \mu \mathrm{g} / \mathrm{ml}$ for olmesartan and $5-25 \mu \mathrm{g} / \mathrm{ml}$ for hydrochlorthiazide.

\section{Study of spectra and selection of wavelength}

All three drugs were scanned over the range of 200-400 nm and overlay spectra was observed. While studding the overlay spectra it was observed that amlodipine shows maximum absorbance at $238.5 \mathrm{~nm}$, olmesartan shows maximum absorbance at $256.5 \mathrm{~nm}$ and hydrochlorthiazide shows peaks at $271.5 \mathrm{~nm}$ and $322 \mathrm{~nm}$. It was observed that hydrochlorthiazide is interfering with amlodipine and olmesartan at absorbance maxima but difference in absorbance maxima is sufficient and spectral characteristics are such that all three drugs can be simultaneously estimated by simultaneous equation method (Figure 2).

*Corresponding author: Hemendra Kumar Sharma, Sagar Institute of Research and Technology-Pharmacy, Ayodhya bypass Road, Bhopal (M.P.) 462036(India), Tel: +917415551032; E-mail: ashu05sharma@gmail.com

Received June 08, 2011; Accepted June 30, 2011; Published July 02, 2011

Citation: Sharma HK, Jain N, Jain SK (2011) Development of Spectrophotometric Method for Quantitative Estimation of Amlodipine Besylate, Olmesartan Medoxomil and Hydrochlorthiazide in Tablet Dosage Form. Pharm Anal Acta 2:126 doi:10.4172/2153-2435.1000126

Copyright: () 2011 Sharma HK, et al. This is an open-access article distributed under the terms of the Creative Commons Attribution License, which permits unrestricted use, distribution, and reproduction in any medium, provided the original author and source are credited. 
<smiles>CCOC(=O)C1=C(COCCN)NC(C)=C(C(=O)OC)C1c1ccccc1Cl</smiles>

Figure-1a<smiles>CCCC1(C)N(c2ccc(-c3ccccc3-c3nnn[nH]3)cc2)C(C(=O)OC)=C(C(C)(C)O)N1c1oc(=O)oc1C</smiles>

Figure-1b

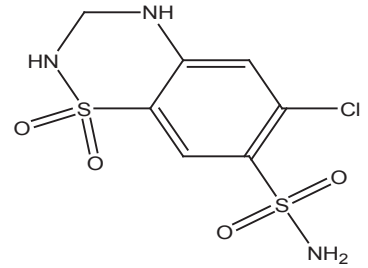

Figure-1c

Figure 1: (a) Structure of amlodipine besylate, (b) Structure of olmesartan medoxomil and (c) Structure of hydrochlorthiazide.

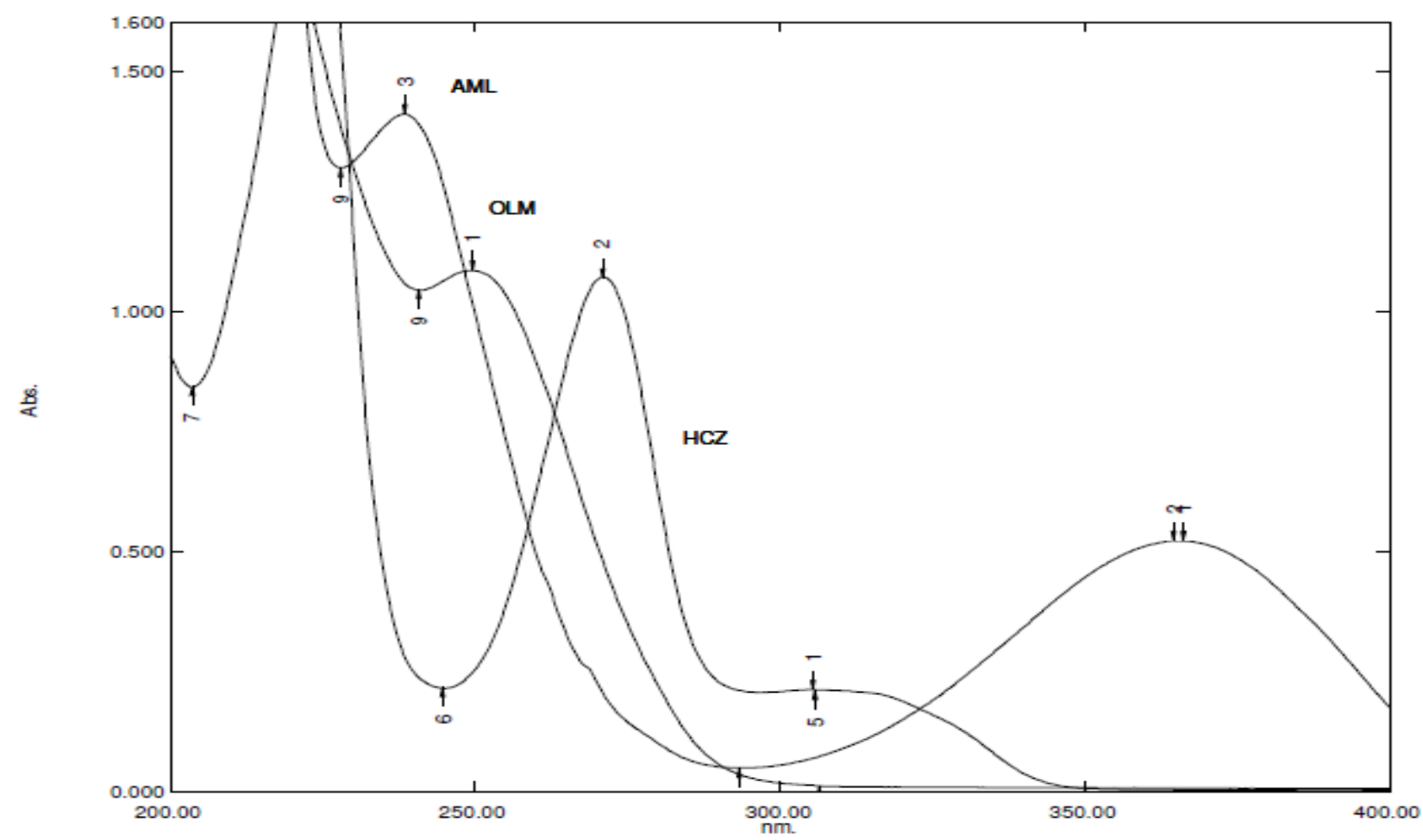

Figure 2: Overlay spectra of amlodipine, olmesartan and hydrochlorthiazide.

The concentration of all three drugs in mixture can be calculated by using following eqns, $C_{A M L}=A_{1}\left(a_{y 2} a_{z 3}-a_{y 3} a_{z 2}\right)-A_{2}\left(a_{y 1} a_{z 3}-a_{y 3} a_{z 1}\right)+A_{3}$ $\left(a_{y 1} a_{z 2}-a_{y 2} a_{z 1}\right) / a_{x 1}\left(a_{y 2} a_{z 3}\right)-a_{x 2}\left(a_{y 1} a_{z 3}-a_{y 3} a_{z 1}\right)+a_{x 3}\left(a_{y 1} a_{z 2}-a_{y 2} a_{z 1}\right) \ldots . .(1), C_{O L M}=$ $A_{1}\left(a_{x 2} a_{z 3}-a_{x 3} a_{z 2}\right)-A_{2}\left(a_{x 1} a_{z 3}-a_{x 3} a_{z 1}\right)+A_{3}\left(a_{x 1} a_{z 2}-a_{x 2} a_{z 1}\right) / a_{y 1}\left(a_{x 2} a_{z 3}\right)-a_{y 2}\left(a_{x 1} a_{z 3}-\right.$ $\left.a_{x 3} a_{z 1}\right)+a_{y 3}\left(a_{x 1} a_{z 2}-a_{x 2} a_{z 1}\right) \ldots . .(2), C_{H C Z}=A_{1}\left(a_{x 2} a_{y 3}-a_{x 3} a_{y 2}\right)-A_{2}\left(a_{x 1} a_{y 3}-a_{x 3} a_{y 1}\right)$ $+A_{3}\left(a_{x 1} a_{y 2}-a_{x 2} a_{y 1}\right) / a_{z 1}\left(a_{x 2} a_{y 3}\right)-a_{z 2}\left(a_{x 1} a_{y 3}-a_{x 3} a_{y 1}\right)+a_{z 3}\left(a_{x 1} a_{y 2}-a_{x 2} a_{y 1}\right) \ldots$. (3), Where $A_{1}, A_{2}$ and $A_{3}$ are the absorbance values of mixture/tablet solution. $a_{x 1} \quad a_{x 2}, a_{x 3}$ are the absorptivities of amlodipine at $238.5 \mathrm{~nm}$, $256.5 \mathrm{~nm}$ and $271.5 \mathrm{~nm}$ respectively. $\mathrm{A}_{\mathrm{y} 1}, \mathrm{a}_{\mathrm{y} 2}$ and $\mathrm{a}_{\mathrm{y} 3}$ are absorptivities of olmesartan $238.5 \mathrm{~nm}, 256.5 \mathrm{~nm}$ and $271.5 \mathrm{~nm}$ respectively. $\mathrm{A}_{\mathrm{z1}}, \mathrm{a}_{\mathrm{z} 2}$ and $\mathrm{a}_{\mathrm{z} 3}$ absorptivities of hydrochlorthiazide $238.5 \mathrm{~nm}, 256.5 \mathrm{~nm}$ and $271.5 \mathrm{~nm}$ respectively. $\mathrm{C}_{\mathrm{AML}}, \mathrm{C}_{\mathrm{OLM}}$ and $\mathrm{C}_{\mathrm{HCZ}}$ are concentration of amlodipine, olmesartan and hydrochlorthiazide respectively.

The absorbtivity of all three drugs were calculated by equation $(\mathrm{A}=$ $a b c)$.

$\begin{array}{lllrll}\mathbf{a x}_{1} & 0.0366 & \mathbf{a y}_{1} & 0.0386 & \mathbf{a z}_{1} & 0.0070 \\ \mathbf{a x}_{2} & 0.0127 & \mathbf{a y}_{2} & 0.0483 & \mathbf{a z}_{2} & 0.0296 \\ \mathbf{a x}_{3} & 0.0045 & \mathbf{a y}_{3} & 0.033 & \mathbf{a z}_{3} & 0.0715\end{array}$

The equation are:

$C_{X}=A_{1}(0.0024763382)-A_{2}(0.002528319)+A_{3}(0.00080425) /$ 
Citation: Sharma HK, Jain N, Jain SK (2011) Development of Spectrophotometric Method for Quantitative Estimation of Amlodipine Besylate, Olmesartan Medoxomil and Hydrochlorthiazide in Tablet Dosage Form. Pharm Anal Acta 2:126. doi:10.4172/2153-2435.1000126

Page 3 of 4

\subsection{4}

$\mathrm{C}_{\mathrm{Y}}=\mathrm{A}_{1}(0.00077485)-\mathrm{A}_{2}(0.0025854)+\mathrm{A}_{3}(0.00099446) /$ 0.00005700193

$\mathrm{C}_{\mathrm{z}}=\mathrm{A}_{1}(0.000202669)-\mathrm{A}_{2}(0.0010371378)+\mathrm{A}_{3}(0.001278658) /$ 0.00006708112

\section{Preparation for analysis of tablet formulation}

Twenty tablets were taken and their average weight was determined. They are crushed to fine powder; amount equivalent to $5 \mathrm{mg}$ of amlodipine was taken in 100-ml volumetric flask. The olmesartan and hydrochlorthiazide present in this amount of tablet powder was $20 \mathrm{mg}$ and $12.5 \mathrm{mg}$, the ratio of all three drugs was 5:20:12.5. This was than dissolve in $50 \mathrm{ml}$ of methanol by sonication for about 10 minutes. The volume is made upto the mark by methanol and filtered by Whatmann filter paper (no.41) and the filtrate was used to prepare samples of different concentration. Now all the tablet samples was scanned in multi photometric mode and the concentration of all three drugs were obtained from the equation. Results of tablet analysis are reported in Table 1.

\section{Validation of Method}

As per ICH guideline the method is validated and following parameters were evaluated.

\section{Linearity}

Linearity of the method was determined by diluting the stock solution to give a concentration range of $5-25 \mu \mathrm{g} / \mathrm{ml}$ for amlodipine, $6-30 \mu \mathrm{g} / \mathrm{ml}$ for olmesartan and $5-25 \mu \mathrm{g} / \mathrm{ml}$ for hydrochlorthiazide. The calibration curve was constructed between concentration verses absorbance.

\section{Precision}

Precision was determined by repeatability, Intermediate precision and reproducibility of all three drugs. Repeatability indicates the precision under the same operating condition over short interval time. The intermediate precision study is expressed within laboratory variation on different days and analyst to analyst variation by different analyst. The reproducibility is expressed in laboratory to laboratory variation.

\section{Accuracy (\% recovery)}

To a preanalyzed tablet solution a definite concentration of pure drug was added $(80 \%, 100 \%$ and $120 \%$ level) and then recovery was studied. A preanalyzed tablet solution containing $5 \mu \mathrm{g} / \mathrm{ml}$ of amlodipine $20 \mu \mathrm{g} / \mathrm{ml}$ of olmesartan and $12.5 \mu \mathrm{g} / \mathrm{ml}$ of hydrochlorthiazide were taken in $10 \mathrm{ml}$ volumetric flasks and known concentrations of pure drug solution was added to them, which were prepared from standard stock solution of amlodipine, olmesartan and hydrochlorthiazide. It was repeated at 5 concentration and 3 replicate level.

\begin{tabular}{|l|l|l|l|l|l|}
\hline S. No & DRUG & MEAN & S.D. & \%COV & Std. Error \\
\hline 1. & AML & 96.05 & 0.094 & 0.095 & 0.092 \\
\hline 2. & OLM & 98.85 & 0.145 & 0.151 & 0.095 \\
\hline 3. & HCZ & 98.7 & 0.23 & 0.246 & 0.224 \\
\hline
\end{tabular}

* $\mathrm{SD}$ is standard deviation, AML is amlodipine besylate, OLM is olmesartan medoxomil and $\mathrm{HCZ}$ is hydrochlorthiazide

Table 1: Result of Tablet formulation.

\begin{tabular}{|l|l|l|l|l|}
\hline S.NO. & PARAMETER & AML & OLM & HCZ \\
\hline 1. & Working $\lambda$ & $238.5 \mathrm{~nm}$ & $256.5 \mathrm{~nm}$ & $271.5 \mathrm{~nm}$ \\
\hline 2. & Beer's law limit $(\mu \mathrm{g} / \mathrm{ml})$ & $5-25$ & $6-30$ & $5-25$ \\
\hline 3. & Correlation Coefficient $\left(\mathrm{r}^{2}\right)^{*}$ & 0.9997 & 0.9998 & 0.9998 \\
\hline 4. & Slope $(\mathrm{m})^{*}$ & 0.046 & 0.043 & 0.072 \\
\hline $\mathbf{5 .}$ & ${\text { Intercept }(\mathrm{c})^{*}}^{*}$ & 0.002 & 0.003 & -0.002 \\
\hline
\end{tabular}

* Value of five replicate and five concentrations

Table 2: Result of Linearity of AML, OLM AND HCZ.

\section{Robustness}

As per ICH norms, small, but deliberate variations by altering the $\mathrm{pH}$ and / or concentration of the solvent were made to check the methods capacity to remain unchanged. The change was made in the ratio of solvent. Instead of 100\%, 95\% methanol was used as solvent.

\section{Results and Discussion}

The simultaneous equation method for estimation of amlodipine, olmesartan and hydrochlorthiazide in tablet dosage form was found to be simple, pricise, accurate and reproducible. The solvent used was $100 \%$ methanol and do not shows any significant interference in the spectrophotometric assay of all three drugs.

\section{Linearity}

The proposed method was found to be linear in the range of 5-25, $6-30$ and $5-25 \mu \mathrm{g} / \mathrm{ml}$ with correlation coefficient $0.9997,0.9998$, and 0.9998 for amlodipine, olmesartan and hydrochlorthiazide respectively. Result of linearity study shown in Table 2.

\section{Precision}

Repeatability: The repeatability was performed for five replicate at five concentrations in linearity range $5,10,15,20$ and $25 \mu \mathrm{g} / \mathrm{ml}$ for amlodipine and hydrochlorthiazide and $6,12,18,24$ and $30 \mu \mathrm{g} / \mathrm{ml}$ for olmesartan indicates the precision under the same operating condition over short interval time.

Intermediate precision: Intermediate precision was also performed within laboratory variation on different days for all three drugs simultaneously in five replicate at five concentrations.

Analyst- to analyst variation: Analyst to analyst variation was performed by different analyst in five replicate at five concentrations.

Reproducibility: The reproducibility was performed in different laboratory (SHIMAZDU 1800 series) in five replicate at five concentrations. Result of precision shown in Table 3.

\section{Accuracy}

The validity and reliability of proposed methods were assessed by recovery studies. The recovery of added standards $(80 \%, 100 \%$ and $120 \%)$ was found at five replicate and five concentrations level. The value of mean of recoveries was found to be in ranging from 98.77 to $99.06 \%$ for amlodipine, 98.89 to $99.34 \%$ for olmesartan and 98.68 to $98.96 \%$ for hydrochlorthiazide. The value of SD and \%RSD are less then 2 indicate the accuracy of method. Result of recovery study shown in Table 3.

\section{Robustness}

Standard stock solution of $1000 \mu \mathrm{g} / \mathrm{ml}$ of amlodipine, olmesartan and hydrochlorthiazide were prepared using 95\% methanol as a solvent. From standard stock solution, sub stock solution of $100 \mu \mathrm{g} /$ $\mathrm{ml}$ of amlodipine, olmesartan and hydrochlorthiazide were prepared 
Citation: Sharma HK, Jain N, Jain SK (2011) Development of Spectrophotometric Method for Quantitative Estimation of Amlodipine Besylate, Olmesartan Medoxomil and Hydrochlorthiazide in Tablet Dosage Form. Pharm Anal Acta 2:126. doi:10.4172/2153-2435.1000126

Page 4 of 4

\begin{tabular}{|c|c|c|c|c|c|c|c|c|c|}
\hline \multirow{2}{*}{$\begin{array}{l}\text { S.NO. } \\
1 .\end{array}$} & \multicolumn{3}{|c|}{ PARAMETER } & \multicolumn{3}{|c|}{$\mathrm{MEAN}^{*} \pm \mathrm{SD}^{*}$} & \multicolumn{3}{|c|}{$\%$ RSD* } \\
\hline & \multicolumn{9}{|c|}{ ACCURACY(RECOVERY STUDY) } \\
\hline & AML & OLM & $\mathrm{HCZ}$ & AML & OLM & $\mathrm{HCZ}$ & AML & OLM & $\mathrm{HCZ}$ \\
\hline & $80 \%$ & $80 \%$ & $80 \%$ & $98.77 \pm 0.03$ & $99.24 \pm 0.02$ & $98.68 \pm 0.04$ & 0.033 & 0.023 & 0.043 \\
\hline & $100 \%$ & $100 \%$ & $100 \%$ & $99.68 \pm 0.04$ & $98.89 \pm 0.02$ & $98.95 \pm 0.05$ & 0.043 & 0.028 & 0.052 \\
\hline & $120 \%$ & $120 \%$ & $120 \%$ & $99.06 \pm 0.03$ & $99.34 \pm 0.02$ & $98.96 \pm 0.03$ & 0.036 & 0.026 & 0.033 \\
\hline \multirow[t]{5}{*}{2.} & \multicolumn{9}{|c|}{ PRICISION } \\
\hline & \multicolumn{3}{|c|}{ a. Repeatability } & $99.9 \pm 0.09$ & $96.27 \pm 0.02$ & $94.08 \pm 0.02$ & 0.496 & 1.142 & 1.140 \\
\hline & \multicolumn{3}{|c|}{ b. Intermediate precision } & $99.38 \pm 0.05$ & $96.40 \pm 0.18$ & $93.68 \pm 0.24$ & 0.481 & 1.075 & 1.073 \\
\hline & \multicolumn{3}{|c|}{ C.Analyst to Analyst } & $99.04 \pm 0.04$ & $96.33 \pm 0.13$ & $93.42 \pm 0.14$ & 0.392 & 0.898 & 0.986 \\
\hline & \multicolumn{3}{|c|}{ d. Reproducibility } & $98.82 \pm 0.03$ & $98.18 \pm 0.10$ & $98.08 \pm 0.06$ & 0.342 & 0.871 & 0.593 \\
\hline 3. & \multicolumn{3}{|c|}{ ROBUSTNESS } & $99.40 \pm 0.09$ & $95.95 \pm 0.14$ & $93.61 \pm 0.23$ & 0.733 & 0.151 & 0.246 \\
\hline
\end{tabular}

Table 3: Result of validation parameter.

separately. From these standard stock solutions of drugs, appropriate dilutions was prepared to get mixed standard solutions of all three drugs in 5:6:5 ratio (amlodipine, olmesartan and hydrochlorthiazide). Results of robustness shown in Table 3.

\section{Acknowledgments}

The authors are thankful to Sun pharmaceuticals, Silvasa(GJ), Plathico pharma Ltd. Dewas and Matrix laboratory Mumbai providing gift samples along with there analytical reports.

\section{Reference}

1. Budavari SE (1996) The Merck Index. (13 ${ }^{\text {th }}$ edt). Whitehouse Station NJ: Merck \& Co. Inc: 6909.

2. Indian Pharmacopoeia (2007) Government of India, The Controller of Publication New Delhi: 96-97, 576-577.

3. British Pharmacopoeia (2009) London: The Stationery Office.

4. The United States Pharmacopoeia (2007) London: The United States Pharmacopoeial Convention 28: 1745

5. Laurence LB, Goodman and Gilman (2006) The pharmacological basis of

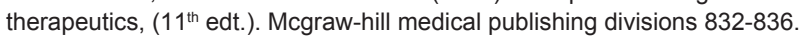

6. Beckett AH, Stenlake JB (2002) Practical pharmaceutical chemistry( $4^{\text {th }}$ edt.). CBS publishers and distributors, New Delhi 275-293.

7. ICH (1994) Harmonised Tripartite Guideline: Code Q2A-Text on Validation of Analytical Procedure Step-3 Consensus Guideline.

8. ICH (1994) Harmonised Tripartite Guideline: Code Q2B- Validation of Analytical Procedure Methodology Step-4 Consensus Guideline.

9. Dhabale PN, Burade KB, Hosmani AH, Rakesh SU, et al. (2009) Development and statistical validation of UV spectrophotometric method for estimation of amlodipine besylate in tablet dosage form. Arch Pharm Sci Res 1: 158-161.

10. Kakde RB, Kotak VH, Barsagade AG, Chaudhary NK, et al. (2008) Spectrophotometric method for simultaneous estimation of amlodipine besylate and bisoprolol fumarate in pharmaceutical preparations. Research J Pharm Tech 1:513-515.

11. Kardile DP, Kalyane NV, Thakkar TH, Patel MR, et al. (2010) Simultaneous spectroscopic estimation of amlodipine besylate and olmesartan medoxomil drug formulations by HPLC and UV-spectrophotometric method. J Pharm Sci Res 2:599-614.

12. Chabukswar AR, Jagdale SC, Kumbhar SV, Kadam VJ, et al. (2010) Simultaneous HPTLC estimation of telmisartan and amlodipine besylate in tablet dosage form. Appl Sci Res 2:94-100.

13. Bhatt J, Singh S, Subbaiah G, Shah B, Kambli S, et al. (2007) A rapid and sensitive liquid chromatography- tandem mass spectrometry (LC-MS/MS) method for estimation of amlodipine in human plasma. Biomed Chromatogr 21: 169-175.

14. Ma Y, Qin F, Sun X, Lu X, Li F (2007) Determination and pharmacokinetic study of amlodipine in human plasma by UPLC-electrospray ionization mass spectrometry. J Pharm Biomed Anal 43: 1540-5.
15. Medhul PK, Srinivas R, Diwan PV (2009) Simultaneous spectroscopic estimation of amlodipine besylate and olmsartan medoximil in tablet dosage form. Asian J Research Chem 2: 127-130.

16. Wankhede SB, Wadkar SB, Raka KC, Chitlange SS (2009) Simultaneous estimation of amlodipine besylate and olmesartan medoxomil in pharmaceutical dosage form. Indian J Pharm Sci 71: 563-567.

17. Kumar AJ, Sathya A, Kumar KS, Sagar P (2010) Simultaneous estimation of olmesartan medoxomil and hydrochlorthiazide by RP-HPLC method from combined dosage forms. Int J Pharm Res Sci 1: 24-27.

18. Yadav N, Srinivasan BP (2010) A validated RP-HPLC and HPTLC method for estimation of olmesartan medoxomil in pharmaceutical dosage form. Der Pharm Chem 2: 103-112.

19. Meyyanathan SN, Rajan S, Muralidharan S, Birajdar AS, Suresh B (2008) A validated RP-HPLC method for simultaneous estimation of nebivolol and hydrochlorthiazide in tablets. Indian J Pharm Sci 70: 687-689.

20. Hemke AT, Bhure MV, Chouhan KS, Gupta KR (2010) UV spectrophotometric determination of hydrochlorthiazide and olmesartan medoxomil in pharmaceutical formulation. E J Chem 7: 1156-1161. 